\title{
Sexual health needs of a patient with mosaic Turner's syndrome
}

\author{
Eileen Bamber, lan Arthur
}

\section{Case report}

A 26-year-old woman, who had previously been diagnosed in childhood with mosaic Turner's syndrome, presented in general practice. The patient had a history of drug dependency and had recently undergone rehabilitation. On presentation she was not being treated for Turner's syndrome, and it appeared that she had had no estrogen replacement therapy for several years. She had been sexually active during this time but had never used any form of contraception, as she understood that she was infertile. She had never had a cervical smear test.

A review of the patient's records showed that she had been referred to a paediatric growth clinic aged 10 years because of short stature, although her height was found to lie between the $3 \mathrm{rd}$ and 10th centiles. It was initially thought that her short stature was constitutional, as she did not exhibit the classical features of Turner's syndrome, but chromosome analysis showed mosaic Turner's syndrome. Some $90 \%$ of the cells were XO with the remaining $10 \%$ being $\mathrm{XX}$, with the second $\mathrm{X}$ appearing as a ring chromosome. Her bone age was delayed by approximately 2 years. Pelvic ultrasound examination revealed no evidence of a uterus or ovaries but this examination did not appear to have been repeated as the patient matured. She was treated initially with subcutaneous growth hormone, with the addition of ethinylestradiol (EE) when aged 11 years, and the introduction of cyclical norethisterone when she developed vaginal bleeding. She had not menstruated spontaneously when oral EE was commenced. Growth hormone was stopped at age 17 years when her height was $155 \mathrm{~cm}$ (9th centile). Her care was then transferred to an endocrinology clinic. It does not appear from her records that she ever attended this clinic.

As part of her initial assessment in primary care the patient underwent a pelvic examination and a cervical smear was taken. The cervix appeared small but inflamed and there was clinical evidence of vaginitis. The smear was reported as showing severe inflammation and probable Trichomonas vaginalis infection. Further testing showed Chlamydia trachomatis infection of the endocervix. Both of these infections were treated appropriately with antimicrobials and the patient was referred to the genitourinary medicine department for further management, including partner notification. Other sexually transmitted infection (STI) investigations proved

\section{J Fam Plann Reprod Health Care 2008; 34(2): 121-122} (Accepted 13 July 2007)

Community Contraceptive Services, Blackpool Primary Care Trust and Quality, Standards and Effectiveness Directorate, North Lancashire Teaching Primary Care Trust, Lancashire, UK

Eileen Bamber, MRCGP, MFSRH, Associate Specialist, General Practitioner and Clinical Advisor

Department of Gynaecology, Blackpool, Fylde and Wyre NHS Trust, Blackpool, UK

Ian Arthur, FRCOG, DM, Consultant Obstetrician and Gynaecologist

Correspondence to: Dr Eileen Bamber, Park Road Medical Practice, 17 Park Road, St Anne's, Lancashire FY8 1PW, UK. E-mail: Eileen.bamber@northlancs.nhs.uk negative and she was started on a course of hepatitis B immunisations. She was also referred to gynaecology outpatients for further assessment of her Turner's syndrome. Blood tests subsequently revealed her hormone levels to be as follows: luteinising hormone (LH) 50.7 IU/1, follicle-stimulating hormone (FSH) 105.5 IU/1 and $17 \beta$-estradiol $<73 \mathrm{pmol} / 1$, all of which were in keeping with a diagnosis of ovarian failure. Pelvic ultrasound examination showed a small postpubertal uterus but no ovaries could be demonstrated. The patient was commenced on the combined oral contraceptive (COC) pill to provide her with hormone replacement therapy (HRT) and protection against the small risk of unplanned pregnancy. She also received advice regarding safer sex. Her smear test was repeated at the appropriate time and was negative. Arrangements were made for a pelvic magnetic resonance imaging scan, and an echocardiogram, but unfortunately the patient's drug dependence syndrome relapsed and she was lost to outpatient follow-up.

\section{Discussion}

Turner's syndrome (or Ullrich-Turner syndrome), which was first described by Ullrich in 1930 and Turner in 1938, is a relatively common chromosomal disorder occurring in approximately 1 in 2000 live births, and is the most commonly occurring chromosome abnormality in women. ${ }^{1}$ The syndrome is caused by complete or partial absence of the second X chromosome, with or without cell line mosaicism. ${ }^{1}$ It has been established that most women with Turner's syndrome do not carry the 'typical' karyotype of 45,X, but several different variants of the karyotype, all exhibiting the same clinical features. ${ }^{2}$ It has been estimated that only about $1 \%$ of $45, \mathrm{X}$ fetuses survive to term and that as many as $10 \%$ of spontaneous miscarriages have a $45, \mathrm{X}$ karyocyte. ${ }^{1}$

Short stature and gonadal dysgenesis are two characteristic features of the condition, but it is now recognised that the syndrome has a wide variety of features that are well documented in the literature. ${ }^{1}$ Many of these characteristics result in increased morbidity and mortality, particularly the cardiovascular and metabolic effects. Some typical features allow the presence of the condition to be suspected prenatally on ultrasound and confirmed by prenatal karyotyping. The condition may be suspected when typical features are noted postnatally, but diagnosis is often delayed into childhood, adolescence and adulthood. ${ }^{2}$

Despite its association with gonadal dysgenesis, $30 \%$ of girls affected with Turner's syndrome will undergo spontaneous puberty. ${ }^{1,2}$ Concerns regarding future risk of osteoporosis and the emotional consequences of delayed puberty lead many clinicians to commence treatment with estrogen therapy fairly early in adolescence, and so affected girls may not know if they would have reached puberty spontaneously. Attaining spontaneous puberty does not, however, equate with fertility and, where it occurs at all, progressive ovarian failure almost invariably follows. ${ }^{1}$ This has lead some researchers to raise the possibility of cryopreservation of ovarian tissue from adolescent girls with Turner's syndrome in order to treat future infertility.1,3-5 Most girls are now treated with a combination of growth hormone, with or without oxandrelone, and HRT. ${ }^{1}$ Affected individuals require 
ongoing medical supervision throughout their adult life, as they are at an increased risk of several common diseases, and a multidisciplinary approach to treatment, preferably in a tertiary centre, is encouraged. ${ }^{1}$

Those individuals who undergo spontaneous puberty and who menstruate may have the potential to achieve spontaneous pregnancy, although most women affected will suffer from primary infertility and would require infertility treatment by oocyte or embryo donation in order to conceive. Women with Turner's syndrome who menstruate normally need to be advised not to postpone pregnancy because of the risk of early and progressive ovarian failure. ${ }^{1}$ There have been many reports of spontaneous pregnancy in Turner's syndrome, more commonly in the mosaic rather than the non-mosaic forms of the condition. ${ }^{4-14}$ The prevalence is estimated at $2-7.6 \% .^{1,4}$ Natural pregnancies have been reported in amenorrhoeic women with Turner's who were receiving HRT, and in those with raised gonadotrophin levels. $1,5,6,8$ In those in whom the degree of infertility has not been established there may be a need for contraceptive advice. ${ }^{5}$ The COC would seem a reasonable choice given the increased risk of osteoporosis in these patients $; 5$ however, the risk of hypertension in these may patients may be a relative contraindication to the COC. ${ }^{1}$ Turner's syndrome is a relative contraindication to pregnancy. It is known that there is a increased risk of miscarriage and of stillbirth in pregnancies of affected individuals, and of chromosomal abnormality or congenital malformation in any offspring, and so genetic counselling may be necessary. $1,4,5,7,10,12$ Oocyte donation and embryo transfer avoids some of these risks and is now an accepted treatment for infertility in Turner's syndrome. ${ }^{1,4}$ In addition, women with Turner's syndrome have an increased cardiovascular morbidity and mortality (particularly related to aortic dissection) during pregnancy, and this can occur in natural pregnancies or those resulting from oocyte donation. $1,4,9,14,15$ The risk of death in women with Turner's syndrome during pregnancy associated with assisted conception has been estimated as 100 times the normal risk. ${ }^{15}$ Counselling on safe sex and the prevention of STIs, and the need for cervical cytology, are just as important for those with Turner's syndrome as for any other sexually active woman.

In our patient the diagnosis was delayed as the only obvious feature of her condition was short stature, and it was not until this was investigated that the diagnosis was made. EE was commenced at the age of 11 years, so that there was no opportunity for the patient to attain spontaneous puberty, and she had never menstruated spontaneously. However, she has had regular withdrawal bleeding when taking $\mathrm{EE}$ and norethisterone, and when taking the COC. She had assumed that she would be infertile and for this reason had never sought contraceptive advice. Although she was sexually active, she did not practise safe sex, and therefore was at high risk of developing STIs. Her elevated LH and FSH levels are in keeping with ovarian failure although there is the possibility of ovarian resistance. Spontaneous pregnancy in a patient with Turner's syndrome with elevated gonadotrophin levels has been reported. 5 In addition to her sexual health needs, the patient needs to be under regular review because of other possible associated health problems such as hypertension, cardiovascular disease, diabetes mellitus and osteoporosis. Many patients affected by Turner's syndrome tend to drift away from medical supervision as they are discharged from paediatric clinics in their teenage years. This appears to have been the case with our patient. The importance of this transition period in the management of Turner's syndrome has been recognised.1,16,17

\section{Conclusions}

Young women with Turner's syndrome should not routinely be assumed to be infertile. Spontaneous pregnancy, although rare, can occur and carries risks for the fetus and the woman concerned. Fertility is an important issue in the management of women with Turner's syndrome and while many individuals will need assisted conception, there are also some who will require contraceptive advice. As with any other sexually active woman, they should be advised regarding safe sex and the need for cervical smear tests. Women who are considering a pregnancy require preconceptual advice and genetic counselling, as well as full medical evaluation.

Statements on funding and competing interests

Funding None identified.

Competing interests None identified.

Acknowledgements

The authors would like to thank Dr John Sweeney, Consultant in GUM, Blackpool Primary Care Trust, for his advice and support with this case report.

\section{References}

1 Saenger P, Albertsson Wikland K, Conway GS, Davenport M, Gravholt $\mathrm{CH}$, Hintz R, et al. Recommendations for the diagnosis and management of Turner syndrome. J Clin Endocrinol Metab 2001; 86: 3061-3069.

2 Gravholt C. Epidemiological, endocrine and metabolic features in Turner syndrome. Eur J Endocrinol 2004; 151: 657-687.

3 Hreinsson JG, Otala M, Fridstrom M. Follicles are found in the ovaries of adolescent girls with Turner's syndrome. J Clin Endocrinol Metab 2002; 87: 3618-3623.

4 Abir R, Fisch B, Nahum R, Orvieto R, Nitke S, Ben Rafael Z. Turner's syndrome and fertility: current status and possible putative prospects. Hum Reprod Update 2001; 7: 603-610.

5 Hovatta O. Pregnancies in women with Turner's syndrome. Ann Med 1999; 31: 106-110.

6 Livadas S, Xekouki P, Kafiri G, Voutetakis A, Maniati-Christidi M, Dacou-Voutetakis C. Spontaneous pregnancy and birth of a normal female from a woman with Turner syndrome and raised gonadotrophins. Fertil Steril 2005; 83: 769-772.

7 Tarani L, Lampariello S, Raguso G, Colloridi F, Pucarelli I, Pasquino AM, et al. Pregnancy in Turner's syndrome: six new cases and review of the literature. Gynecol Endocrinol 1998; 12: 83-87.

8 Birkebaek NH, Crüger D, Hansen J, Nielsen J, Bruun-Petersen G. Fertility and pregnancy outcome in Danish women with Turner syndrome. Clin Genet 2002; 61: 35-39.

9 Landin-Wilhelmsen K, Bryman I, Hanson C, Hanson L. Spontaneous pregnancies in a Turner syndrome woman with $Y$ chromosome mosaicism. J Assist Reprod Genet 2004; 21: 229-230.

10 Cools M, Rooman RP, Wauters J, Jacqemyn Y, Du Caju MV. A non-mosaic 45,X karyotype in a mother with Turner's syndrome and in her daughter. Fertil Steril 2004; 82: 923-925.

11 Kulkarni A, Wardle P. Pregnancies at a late reproductive age in a patient with Turner's syndrome: case report and review of the literature. J Matern Fetal Neonatal Med 2006; 19: 65-66.

12 Acharya G, Jonsrud C, van der Hagen C, Maltau JM. Prenatal diagnosis of fetal hydrops associated with Down's syndrome in a 40-year old woman with a mosaic Turner's karyotype (45,X/47,XXX). Acta Obstet Gynecol Scand 2003; 82: 773-774.

13 Yuge A, Takai N, Nishida Y, Narahara H, Miyakawa I. Spontaneous pregnancy in a 45,X/46,X,r(X) Turner's mosaic patient. Acta Obstet Gynecol Scand 2003; 82: 775-776.

14 Garvey P, Elovitz M, Landsberger EJ. Aortic dissection and myocardial infarction in a pregnant patient with Turner syndrome. Obstet Gynecol 1998; 91(5 Pt 2): 864.

15 The Practice Committee of the American Society of Reproductive Medicine. Increased maternal cardiovascular mortality associated with pregnancy in women with Turner syndrome. Fertil Steril 2005; 83: 1074-1075.

16 Batch J. Turner syndrome in childhood and adolescence. Best Pract Res Clin Endocrinol Metab 2002; 16: 465-482.

17 Donaldson MDC, Gault EJ, Tan TW, Dunger DB. Optimising management in Turner syndrome: from infancy to adult transfer. Arch Dis Child 2006; 91: 513-520. 